\title{
Characteristics of patients referred to Canary Island pneumology outpatient services for chronic obstructive pulmonary disease: the EPOCan study
}

\author{
Juan Marco Figueira-Gonçalves ${ }^{1,2^{*}}$, José María Hernández-Pérez ${ }^{1}$, Carlos Cabrera-López ${ }^{3}$, \\ Aurelio Luis Wangüemert-Pérez ${ }^{4}$, Ignacio García-Talavera' ${ }^{\text {, Yolanda Ramallo-Fariña }}{ }^{5}$, Carolina Ramos-Izquierdo ${ }^{1}$, \\ Luis Manuel González-García ${ }^{6}$ and Sara Guanche-Dorta ${ }^{4}$
}

\begin{abstract}
Objective: Assessing patients with chronic obstructive pulmonary disease (COPD) accounts for 30\% of all pneumology outpatient evaluations. COPD is a heterogeneous disease and generates a massive public health problem. Overall morbidity, particularly cardiovascular disease, challenges patient management. This is an observational, multicentre study, performed at four hospitals in the Canary Islands (Spain), aimed at characterising patients with COPD referred to pneumology outpatient services. Demographic variables, lung function, and morbidity were assessed.

Results: Of the 877 included patients, $44.9 \%$ were active smokers with a mean ( \pm SD) age of $68.2 \pm 10.3$ years. The median (IQR) score for the Charlson comorbidity index was 2 (2), and $70.6 \%$ of the patients were assigned high risk according to the Spanish Guidelines for COPD (GesEPOC) 2021. The degree of airflow obstruction defined by the GOLD 2021 stages 1, 2, 3, and 4 corresponded to 13.6\%, 49\%, 31\%, and 6.3\% of patients, respectively. The most frequently associated morbidities were arterial hypertension (59.5\%), dyslipidaemia (54.3\%), and type 2 diabetes mellitus (31.2\%); $32 \%$ of the patients suffered heart disease. There is a high prevalence of active smoking, type 2 diabetes mellitus, and heart disease in patients referred for COPD to Canary Island pneumology outpatient services.
\end{abstract}

Keywords: Chronic obstructive pulmonary disease, COPD, Cardiovascular, Morbidity

\section{Introduction}

Chronic obstructive pulmonary disease (COPD) constitutes a public health problem with a huge impact on socio-economic costs [1-3]. The disease is one of the most frequent reasons to seek medical care and accounts for $10 \%$ of primary care and $30 \%$ of respiratory outpatient attention [1]. Moreover, COPD is a complex and

\footnotetext{
*Correspondence: juanmarcofigueira@gmail.com

1 Pneumology and Thoracic Surgery Service, Unit for Patients with Highly Complex COPD, University Hospital Nuestra Señora de Candelaria, Santa Cruz de Tenerife, Spain

Full list of author information is available at the end of the article
}

heterogeneous disease, characterised by chronic, barely reversible airflow limitation, mainly-at least in high human development index countries-on account of tobacco smoke [4].

A range of studies has focused on the high morbidity in these patients, which worsens their prognosis and results in additional challenges in their management [5-9]. The cardiovascular morbidity rate of patients with COPD in the Canary Islands seems to exceed the national level $[10,11]$. To corroborate this observation, we performed a multicentre study assessing characteristics of patients 
with COPD who had been referred to pneumology outpatient services in the Canary archipelago.

\section{Main text \\ Methods \\ Study design}

An observational, cross-sectional, multicentre study was performed involving four historical cohorts of outpatients with COPD from the University Hospital Nuestra Señora de Candelaria (Tenerife), the Hospital San Juan de Dios (Tenerife), the University Hospital Dr. Negrín (Gran Canaria), and La Palma General Hospital (La Palma). The retrieved data covers a period from 2011 to 2020.

\section{Study population}

The study included 877 COPD patients where the following inclusion criteria were applied: (1) patient attending follow up in an outpatient pneumology service; (2) age $>40$ years; (3) active or former smoker with a packyear index $(\mathrm{PYI}) \geq 10$ or exposition to another known risk factor like smoke from home cooking and heating fuels, occupational dust or other chemicals; (4) a forced expiratory volume in $1 \mathrm{~s}\left(\mathrm{FEV}_{1}\right) /$ forced vital capacity (FVC) ratio $<70 \%$ upon administration of $400 \mu \mathrm{g}$ of salbutamol. The presence of chronic respiratory diseases other than COPD, e.g., interstitial lung disease or pneumoconiosis, was considered an exclusion criterion, except historial of asthma.

\section{Ethical approval}

Clinical data extraction from electronic, medical records was authorised by the corresponding ethics committees (Ethics Committee for Clinical Research of the University Hospital Nuestra Señora de Candelaria, registry number CHUNSC_2021_41). Data were de-identified for analysis. In this study, informed consent was waived for its retrospective, non-interventional design and the use of anonymous clinical data.

\section{Variables}

Variables included in the analyses were age, gender, body mass index (BMI $\left[\mathrm{kg} / \mathrm{m}^{2}\right]$ ), history of tobacco consumption assessed as PYI, peripheral oxygen saturation by means of pulse oximetry (SpO2)-performed with the patient at rest in a sitting position-dyspnoea assessment using the modified Medical Research Council scale (mMRC scale), long-term home oxygen therapy and/or bi-level positive airway pressure (BiPAP) or continuous positive airway pressure ventilation (CPAP), the presence of chronic mucus hypersecretion, and the number of severe exacerbations requiring hospital stays during the year prior to the first visit as an outpatient. Chronic mucus hypersecretion was registered in all the corresponding databases. Previous admissions were confirmed reviewing hospital records. Data on the associated morbidities arterial hypertension (AHT), type 2 diabetes mellitus (T2DM), dyslipidaemia (DLP), obesity (defined as $\left.B M I \geq 30 \mathrm{~kg} / \mathrm{m}^{2}\right)$, underweight $\left(B M I<18.5 \mathrm{~kg} / \mathrm{m}^{2}\right)$, atrial fibrillation (AF), ischaemic heart disease (IHD), chronic heart failure (CHF), cerebrovascular accidents (CVA), neoplasia (solid tumours, lymphoma, leukaemia), osteoporosis, and mood disorders (anxiety and depression) were obtained. Each associated morbidity was confirmed by a comprehensive review of the electronic, medical records, data from diagnostic procedures, and disease-specific therapies. The Charlson comorbidity index (CCI) not age-adjusted score [12] and the BODEx index were determined for each patient. Forced spirometry data following bronchodilation was recorded as $\mathrm{FEV}_{1} \%, \mathrm{FVC} \%$, and the $\mathrm{FEV}_{1} / \mathrm{FVC}$ ratio. The patients' degree of airflow obstruction was classified according to the Global Initiative for Chronic Obstructive Lung Disease (GOLD) document 2021 [4]. Based on the Spanish guidelines GesEPOC 2021, patients were also classified as low risk vs high risk patients [13].

\section{Statistical analysis}

In agreement with published work [14], the representative sample size for the population with COPD in the Canary Islands was 599. This number was calculated taking into account the approximately 240,000 persons with COPD in the Canary Islands and the total of 2,500,000 inhabitants. An estimation error of $4 \%$, a significance level of $5 \%$, and a power of $80 \%$ were assumed. In addition, a maximum probability of $50 \%$ was considered to meet the sample size requirements for the different features of interest.

Qualitative variables were summarised as frequencies and percentages and continuous variables as means and standard deviations or median and interquartile range according to the normality of their distribution. For continuous normal variables, bivariate comparisons between independent samples were made using Student's t test. The Mann Whitney U test was used for continuous nonnormal variables. Qualitative variables were tested by means of Chi-square or Fisher's exact test, as applicable. A p-value of $<0.05$ was considered statistically significant. Analyses were performed using SPSS v.21 software.

\section{Results}

The baseline characteristics of the 877 patients-comprising study population are given in Table 1 . The patients' mean $( \pm$ SD) age was $68.2 \pm 10.3$ years, $44.9 \%$ were active smokers and $20.1 \%$ of the population were women. The baseline characteristics of the patients according smoking status are given in Additional file 1: Table S1. The 
Table 1 Baseline characteristics of patients with chronic obstructive pulmonary disease according to lung function and degree of dyspnoea

\begin{tabular}{|c|c|c|c|c|c|c|c|}
\hline & $\begin{array}{l}\text { Study } \\
\text { population } \\
(\mathrm{n}=877)\end{array}$ & $\begin{array}{l}\mathrm{FEV}_{1}<50 \% \\
(\mathrm{n}=328 \\
37.4 \%)\end{array}$ & $\begin{array}{l}\mathrm{FEV}_{1} \geq 50 \% \\
(\mathrm{n}=549 ; \\
62.6 \%)\end{array}$ & p-value & $\begin{array}{l}m M R C<2 \\
(n=432 ; \\
49.3 \%)\end{array}$ & $\begin{array}{l}\operatorname{mMRC} \geq 2 \\
(n=445 ; \\
50.7 \%)\end{array}$ & p-value \\
\hline \multicolumn{8}{|l|}{ Clinical data } \\
\hline Mean age, years (SD) & $68.2(10.4)$ & $69(10.1)$ & $67.7(10.5)$ & 0.12 & $66.4(10.2)$ & $69.9(10.3)$ & $<0.001$ \\
\hline Female, n (\%) & $176(20.1)$ & $70(21.3)$ & $106(19.3)$ & 0.467 & $90(20.8)$ & $86(19.3)$ & 0.577 \\
\hline Mean pack-year index (SD) & $47.4(27.5)$ & $51.08(26.7)$ & $45.2(27.8)$ & $<0.001$ & $46.2(26.8)$ & $48.6(28.2)$ & 0.187 \\
\hline Active smoker, $\mathrm{n}(\%)$ & $394(44.9)$ & $140(42.7)$ & $254(46.3)$ & 0.584 & $186(43.1)$ & $208(46.7)$ & 0.240 \\
\hline Mean dyspnoea, mMRC score (SD) & $1.6(0.82)$ & $1.9(0.89)$ & $1.4(0.71)$ & $<0.001$ & $0.87(0.34)$ & $2.3(0.52)$ & $<0.001$ \\
\hline $\mathrm{mMRC}$ score $\geq 2, \mathrm{n}(\%)$ & $445(50.7 \%)$ & $221(67.4)$ & $224(40.8)$ & $<0.001$ & - & - & - \\
\hline Mean BMI (SD) & $27.3(5.3)$ & $27.1(5.7)$ & $27.5(5.09)$ & 0.109 & $26.8(5.1)$ & $27.8(5.5)$ & 0.01 \\
\hline $\begin{array}{l}\text { Median severe exacerbations in the previous } \\
\text { year (IQR) }\end{array}$ & $0(0)$ & $0(0)$ & $0(0)$ & $<0.001$ & $1(1)$ & $2(2)$ & 0.001 \\
\hline $\begin{array}{l}\geq 1 \text { severe exacerbations in the previous } \\
\text { year, } n(\%)\end{array}$ & $147(16.8)$ & $76(23.2)$ & $71(12.9)$ & $<0.001$ & $54(12.5)$ & $93(20.9)$ & 0.001 \\
\hline Median BODEx index (IQR) & $2(2)$ & $3(2)$ & $1(2)$ & $<0.001$ & $1(2)$ & $3(2)$ & $<0.001$ \\
\hline BODEx $>4, n(\%)$ & $80(9.1)$ & $77(23.5)$ & $3(0.5)$ & $<0.001$ & $6(1.74)$ & $74(16.6)$ & $<0.001$ \\
\hline Mucus hypersecretion, n (\%) & $394(44.9)$ & $166(50.6)$ & $228(41.5)$ & 0.009 & $173(40)$ & $221(49.7)$ & 0.004 \\
\hline Long-term home oxygen therapy, n (\%) & $133(15.2)$ & $91(27.7)$ & $42(7.7)$ & $<0.001$ & $38(8.8)$ & $95(21.3)$ & $<0.001$ \\
\hline BiPAP or CPAP, $n(\%)$ & $62(8.4)$ & $38(14)$ & $24(5.1)$ & $<0.001$ & $19(5.4)$ & $43(11.1)$ & 0.006 \\
\hline Mean no. diseases (SD) & $2.61(1.75)$ & $2.58(1.70)$ & $2.63(1.79)$ & 0.98 & $2.25(1.59)$ & $2.95(1.83)$ & $<0.001$ \\
\hline \multicolumn{8}{|l|}{ Functional parameters } \\
\hline $\mathrm{FEV}_{1} / \mathrm{FVC}$ & $56.16(11.0)$ & $48.88(11.5)$ & $60.5(8.1)$ & $<0.001$ & $58.42(9.7)$ & $53.97(11.8)$ & $<0.001$ \\
\hline $\mathrm{FEV}_{1}(\%)$ & $57.9(19.5)$ & $38.36(8.4)$ & $69.6(14.1)$ & $<0.001$ & $63.52(18.6)$ & $52.44(18.7)$ & $<0.001$ \\
\hline FVC (\%) & $80.45(21.89)$ & $66.76(18.75)$ & $88.62(19.43)$ & $<0.001$ & $85.3(21.7)$ & $75.8(21.1)$ & $<0.001$ \\
\hline $\mathrm{FEV}_{1} \geq 50 \%, \mathrm{n}(\%)$ & $549(62.6 \%)$ & - & - & & $325(75.2)$ & $224(50.3)$ & $<0.001$ \\
\hline Mean baseline SpO2, \% (SD) & $95.3(2.1)$ & $94.5(2.4)$ & $95.7(1.6)$ & $<0.001$ & $95.8(1.8)$ & $94.82(2.2)$ & $<0.001$ \\
\hline \multicolumn{8}{|l|}{ Morbidities, n (\%) } \\
\hline Arterial hypertension & $522(59.5)$ & $197(60.1)$ & $325(59.2)$ & 0.801 & $234(54.2)$ & $288(64.7)$ & 0.001 \\
\hline Type 2 diabetes mellitus & $274(31.2)$ & $106(32.3)$ & $168(30.6)$ & 0.596 & $100(23.1)$ & $174(39.1)$ & $<0.001$ \\
\hline Dyslipidemia & $476(54.3)$ & $167(50.9)$ & $309(56.3)$ & 0.122 & $222(51.4)$ & $254(57.1)$ & 0.091 \\
\hline Obesity & $239(27.3)$ & $88(26.8)$ & $151(27.5)$ & 0.073 & $99(22.9)$ & $140(31.5)$ & 0.037 \\
\hline Underweight & $33(3.8)$ & $16(4.9)$ & $17(3.1)$ & 0.073 & $19(4.4)$ & $14(3.1)$ & 0.037 \\
\hline Ischaemic heart disease & $151(17.2)$ & $46(14)$ & $105(19.1)$ & 0.053 & $52(12)$ & $99(22.2)$ & $<0.001$ \\
\hline Heart failure & $94(10.7)$ & $40(12.2)$ & $54(9.8)$ & 0.275 & $34(7.9)$ & $60(13.5)$ & 0.007 \\
\hline Atrial fibrillation & $152(17.3)$ & $54(16.5)$ & $98(17.9)$ & 0.599 & $54(12.5)$ & $98(22)$ & $<0.001$ \\
\hline Heart disease & $281(32)$ & $101(30.8)$ & $180(32.8)$ & 0.54 & $104(24.1)$ & $177(39.8$ & $<0.001$ \\
\hline Cerebrovascular accident & $71(8.1)$ & $28(8.5)$ & $43(7.8)$ & 0.711 & $29(6.7)$ & $42(9.4)$ & 0.139 \\
\hline Mood disorder & $57(6.5)$ & $24(7.3)$ & $33(6)$ & 0.448 & $29(6.7)$ & $28(6.3)$ & 0.800 \\
\hline Osteoporosis & $17(1.9)$ & $10(3)$ & $7(1.3)$ & 0.065 & $8(1.9)$ & $9(2)$ & 0.855 \\
\hline Bronchial asthma & $111(12.7)$ & $48(14.6)$ & $63(11.5)$ & 0.173 & $56(13)$ & $55(12.4)$ & 0.788 \\
\hline Neoplasia & $126(14.4)$ & 41 (12.5) & 85 (15.5) & 0.223 & $56(13)$ & $70(15.7)$ & 0.243 \\
\hline $\mathrm{CCl} \geq 3$ & $292(33.3)$ & $105(32.1)$ & $187(34.1)$ & 0.533 & $106(24.5)$ & $186(41.9)$ & $<0.001$ \\
\hline $\mathrm{CCl}$, median (IQR) & $2(2)$ & $2(2)$ & $2(2)$ & 0.545 & $1(1)$ & $2(2)$ & $<0.001$ \\
\hline
\end{tabular}

Bold indicates $p$ value $<0.05$

$B M I$ body mass index; $F E V$, forced expiratory volume in $1 \mathrm{~s}$; FVC forced vital capacity; $C C I$ Charlson comorbidity index score, not age-adjusted; $m M R C$ modified Medical Research Council scale; $S p O 2$ peripheral oxygen saturation by means of pulse oximetry measured with the patient at rest in a sitting position; BiPAP bi-level positive airway pressure; CPAP continuous positive airway pressure; IQR interquartile range 
GOLD document 2021 stages 1, 2, 3, and 4, which define the degree of airflow obstruction, corresponded to 13.6, 49,31 , and $6.3 \%$ of the patients, respectively. The mean $( \pm \mathrm{SD}) \% \mathrm{FEV}_{1}$ was $57.9 \%( \pm 19.45)$, the median CCI was $2(\mathrm{IQR}=2)$, and $70.6 \%$ were considered high risk patients according to GesEPOC 2021. The most frequently associated morbidities were AHT (59.5\%), DLP (54.3\%), and T2DM (31.2\%).

\section{Patient characteristics by sub-groups According to lung function}

Compared to patients with mild to moderate airflow obstruction, patients with $\mathrm{FEV}_{1}<50 \%$ had a higher smoking load (PYI $45.2 \pm 27.7$ vs $51.1 \pm 26.7 ; \mathrm{p}<0.001$ ) and higher percentage of patients that required hospital admission in the previous year $(12.9 \%$ vs $23.2 \%$; $\mathrm{p}<0.001)$. As to associated morbidities, no significant difference was detected (Table 1).

\section{According to degree of dyspnoea}

More aged individuals were detected in patients with $m M R C \geq 2$ than in patients with a lower degree of dyspnoea $(69.9 \pm 10.3$ vs $66.4 \pm 10.2 ; \mathrm{p}<0.001)$. Table 1 details that the former also had a higher percentage of patients that required hospital admission in the previous year (20.9\% vs $12.5 \% ; \mathrm{p}<0.001)$, higher CCI scores (median 2 $(\mathrm{IQR}=2)$ vs $1(\mathrm{IQR}=1) ; \mathrm{p}<0.001)$, and a higher prevalence of cardiovascular morbidities.

According to history of exacerbations requiring hospital stays Patients with hospital stays for exacerbation prior to attending outpatient services were older $(70.1 \pm 11.03$ years vs $67.8 \pm 10.22$ years; $\mathrm{p}<0.001)$ compared to individuals without hospital stays, had a higher percentage of patients with CCI score $\geq 3$ ( 45.6 vs $30.9 \%$; $\mathrm{p}<0.001$ ), and a higher prevalence of cardiovascular morbidities and conditions related to mood disorders (Table 2).

\section{According to the GesEPOC 2021 risk groups}

Patients designated as high risk patients were slightly older than the low risk patients $(69.06 \pm 10.22$ years vs $66.17 \pm 10.53$ years; $\mathrm{p}<0.001$ ), had a higher smoking load (PYI $48.77 \pm 28.34$ vs $44.10 \pm 25.05 ; \mathrm{p}<0.001$ ) and a higher prevalence of cardiovascular diseases (Table 3, Additional file 2: Fig. S1).

\section{Discussion}

In our study, most of the patients were men between 60 and 80 years of age, mostly overweight, with a moderate to severe degree of airflow obstruction, and heavy tobacco consumption (PYI $>40$ ). Although these characteristics are in line with similar national studies [15], it is particularly striking that up to $45 \%$ of the patients were active smokers. This percentage was even observed in highly symptomatic patients. In the Spanish IBERPOC and the ESPIRAL-ES study, 30-55\% of the outpatients with COPD were found to continue smoking [16, 17]. The EPOConsul audit of 28 hospitals throughout Spain evaluated the management of patients with COPD through pneumology outpatient follow up and presented a rate of about $31 \%$ of active smokers, which is below our regional data [15]. Treatment for smoking cessation is the primary and most cost-effective therapeutic intervention in COPD management [18-20].

Notwithstanding, different studies have revealed that patients with COPD are distinguishable from other smokers insofar as they have a higher degree of dependence and less motivation to quit smoking [21-23]. In addition, tobacco is cheaper in the Canary Islands than on the Spanish mainland and, therefore, more accessible, which could further encourage continued tobacco use in these patients [24]. Moreover, particularly the western Canary Islands have been among the few Spanish regions where tobacco played a major role in their commercial and industrial development. As a result, tobacco use is deep-rooted in the popular culture of the archipelago, which may affect the local perception of its healththreatening effects [25]. The detected high percentage of actively smoking COPD patients in our region shows the need for improved smoking cessation programs.

The patients with COPD on the Canary archipelago exhibit a high prevalence of T2DM and heart disease. T2DM was diagnosed in $30 \%$ of our patients. In patients with COPD, T2DM is a common morbidity [26-29], which is related to heart and kidney disease pathogenesis, these latter associated with a higher risk of exacerbation, more symptoms, and poorer survival [30-35]. In the context of cardiovascular disease, the prevalence of cardiac arrhythmia and IHD in the Canary Island population with COPD is approximately $18 \%$. Remarkably, 1 in 3 patients, who were designated high risk according GesEPOC 2021, had some type of heart disease (i.e., cardiac arrhythmia, HF, or IHD). National studies describe a prevalence of cardiac arrhythmia and IHD of about 16\% and $12 \%$, respectively $[27,28,36]$, which is substantially lower than observed in the Canary archipelago. This data reveals the need to actively search for heart disease in patients with COPD, especially when they belong to the GesEPOC 2021 high-risk group [8].

Of note, patients with COPD who had a history of severe exacerbations exhibited a high prevalence of active smoking, T2DM, and heart disease. A national study performed in 129 hospitals throughout the Spanish territory, with more than 5000 patients included, analysed the characteristics of patients admitted for COPD 
Table 2 Baseline characteristics of patients with chronic obstructive pulmonary disease according to previous hospital stays for exacerbation

\begin{tabular}{|c|c|c|c|}
\hline & \multicolumn{2}{|c|}{ Hospital stay in the previous year } & \multirow[b]{2}{*}{ p-value } \\
\hline & No $(n=730 ; 83.2 \%)$ & Yes $(n=147 ; 16.8 \%)$ & \\
\hline \multicolumn{4}{|l|}{ Clinical data } \\
\hline Mean age, years (SD) & $67.8(10.2)$ & $70.2(11.0)$ & 0.008 \\
\hline Female, n (\%) & $148(20.3)$ & $28(19)$ & 0.735 \\
\hline Mean pack-year index (SD) & $47.3(26.6)$ & $47.9(31.8)$ & 0.802 \\
\hline Active smoker, $\mathrm{n}(\%)$ & $339(46.4)$ & $55(37.4)$ & 0.072 \\
\hline Mean dyspnoea, mMRC score (SD) & $1.5(0.83)$ & $1.73(0.8)$ & $<0.001$ \\
\hline $\mathrm{mMRC}$ score $\geq 2, \mathrm{n}(\%)$ & $352(48.2)$ & $93(63.3)$ & 0.001 \\
\hline Mean BMI (SD) & $27.5(5.5)$ & $26.7(4.6)$ & 0.173 \\
\hline Median severe exacerbations in the previous year (IQR) & $0(0)$ & $1(1)$ & $<0.001$ \\
\hline$\geq 1$ severe exacerbations in the previous year, $n(\%)$ & $0(0)$ & $45(3.4)$ & $<0.001$ \\
\hline Median BODEx index (IQR) & $2(2)$ & $3(2)$ & $<0.001$ \\
\hline BODEx $>4, n(\%)$ & $51(7)$ & $29(19.7)$ & $<0.001$ \\
\hline Mucus hypersecretion, n (\%) & $313(42.9)$ & $81(55.1)$ & 0.007 \\
\hline Long-term home oxygen therapy, n (\%) & $84(11.5)$ & 49 (33.3) & $<0.001$ \\
\hline BiPAP or CPAP, $n(\%)$ & $40(6.6)$ & $22(16.5)$ & $<0.001$ \\
\hline Mean no. diseases (SD) & $3(1.86)$ & $2.53(1.72)$ & 0.004 \\
\hline \multicolumn{4}{|l|}{ Functional parameters } \\
\hline $\mathrm{FEV}_{1} / \mathrm{FVC}$ & $56.6(10.7)$ & $54.1(12.6)$ & $<0.001$ \\
\hline $\mathrm{FEV}_{1}(\%)$ & $59.1(19.0)$ & $51.9(20.8)$ & $<0.001$ \\
\hline FVC (\%) & $81.9(21.6)$ & $73.1(21.8)$ & $<0.001$ \\
\hline $\mathrm{FEV}_{1} \geq 50 \%, \mathrm{n}(\%)$ & $478(65.5)$ & $71(48.3)$ & $<0.001$ \\
\hline Mean baseline SpO2, \% (SD) & $95.4(2.0)$ & $94.7(2.4)$ & $<0.001$ \\
\hline \multicolumn{4}{|l|}{ Morbidities, n (\%) } \\
\hline Arterial hypertension & $432(59.2)$ & $90(61.2)$ & 0.645 \\
\hline Type 2 diabetes mellitus & $214(29.3)$ & $60(40.8)$ & 0.006 \\
\hline Dyslipidemia & $403(55.2)$ & $73(49.7)$ & 0.218 \\
\hline Obesity & $202(27.7)$ & $37(25.2)$ & 0.361 \\
\hline Underweight & $29(4)$ & $4(2.7)$ & 0.361 \\
\hline Ischaemic heart disease & $111(15.2)$ & $40(27.2)$ & $<0.001$ \\
\hline Heart failure & $70(9.6)$ & $24(16.3)$ & 0.016 \\
\hline Atrial fibrillation & $117(16)$ & 35 (23.8) & 0.023 \\
\hline Heart disease & $218(29.9)$ & $63(42.9)$ & 0.002 \\
\hline Cerebrovascular accident & $50(6.8)$ & $21(14.3)$ & 0.003 \\
\hline Mood disorder & $41(5.6)$ & $16(10.9)$ & 0.018 \\
\hline Osteoporosis & $14(1.9)$ & $3(2)$ & 0.921 \\
\hline Bronchial asthma & $91(12.5)$ & $20(13.6)$ & 0.705 \\
\hline Neoplasia & $100(13.7)$ & $26(17.7)$ & 0.208 \\
\hline $\mathrm{CCl} \geq 3$ & $225(30.9)$ & $67(45.6)$ & 0.001 \\
\hline $\mathrm{CCl}$, median (IQR) & $2(2)$ & $2(2)$ & $<0.001$ \\
\hline
\end{tabular}

Bold indicates $\mathrm{p}$ value $<0.05$

$B M I$ body mass index; $F E V$ forced expiratory volume in $1 \mathrm{~s}$; $F V C$ forced vital capacity; $C C I$ Charlson comorbidity index score, not age-adjusted; $m M R C$ modified Medical Research Council scale; SpO2 peripheral oxygen saturation by means of pulse oximetry measured with the patient at rest in a sitting position; BiPAP bi-level positive airway pressure; CPAP continuous positive airway pressure; IQR interquartile range

exacerbation and evidenced a prevalence of active smoking, T2DM, and heart disease of 30, 26, and 30\%, respectively, clearly below the prevalence detected in our study
(37, 40, 43\%, respectively) [37]. All these factors can impact on the clinical progress of these patients in hospital $[6,38,39]$. However, conclusions from our sample 
Table 3 Baseline characteristics of patients with chronic obstructive pulmonary disease according to the Spanish guidelines GesEPOC 2021 risk groups

\begin{tabular}{|c|c|c|c|}
\hline & $\begin{array}{l}\text { Low risk patients }(\mathrm{n}=258 \text {; } \\
29.4 \%)\end{array}$ & $\begin{array}{l}\text { High risk patients }(n=619 \text {; } \\
70.6 \%)\end{array}$ & p-value \\
\hline \multicolumn{4}{|l|}{ Clinical data } \\
\hline Mean age, years (SD) & $66.2(10.5)$ & $69.1(10.2)$ & $<0.001$ \\
\hline Female, n (\%) & $51(19.8)$ & $125(20.2)$ & 0.915 \\
\hline Mean pack-year index (SD) & $44.1(25.1)$ & $48.77(28.3)$ & 0.023 \\
\hline Active smoker, $\mathrm{n}(\%)$ & $117(45.5)$ & $277(44.7)$ & 0.032 \\
\hline mMRC score $\geq 2, n(\%)$ & $0(0)$ & $442(71.5)$ & $<0.001$ \\
\hline Mean BMI (SD) & $27.1(5.09)$ & $27.4(5.44)$ & 0.587 \\
\hline Median severe exacerbations in the previous year (IQR) & $0(0)$ & $0(0)$ & $<0.001$ \\
\hline$\geq 1$ severe exacerbations in the previous year, $\mathrm{n}(\%)$ & $0(0)$ & $147(23.7)$ & $<0.001$ \\
\hline Median BODEx index (IQR) & $0(1)$ & $2(2)$ & $<0.001$ \\
\hline BODEx $>4, n(\%)$ & $0(0)$ & $80(12.9)$ & $<0.001$ \\
\hline Mucus hypersecretion, n (\%) & $86(33.5)$ & $308(49.7)$ & $<0.001$ \\
\hline Long-term home oxygen therapy, n (\%) & $9(3.5)$ & $124(20)$ & $<0.001$ \\
\hline BiPAP or CPAP, $n(\%)$ & $3(1.5)$ & $59(11.1)$ & $<0.001$ \\
\hline \multicolumn{4}{|l|}{ Functional parameters } \\
\hline $\mathrm{FEV}_{1} / \mathrm{FVC}$ & $61.1(7.7)$ & $54.1(11.6)$ & $<0.001$ \\
\hline $\mathrm{FEV}_{1}(\%)$ & $71.2(15.0)$ & $52.4(18.4)$ & $<0.001$ \\
\hline FVC (\%) & $91(21.3)$ & $76.1(20.6)$ & $<0.001$ \\
\hline $\mathrm{FEV}_{1} \geq 50 \%, \mathrm{n}(\%)$ & $257(100)$ & $297(47.9)$ & $<0.001$ \\
\hline Mean baseline SpO2, \% (SD) & $96.1(1.5)$ & $94.97(2.2)$ & $<0.001$ \\
\hline \multicolumn{4}{|l|}{ Morbidities, n (\%) } \\
\hline Arterial hypertension & $142(55.3)$ & $380(61.3)$ & 0.097 \\
\hline Type 2 diabetes mellitus & $51(19.8)$ & $223(36)$ & $<0.001$ \\
\hline Dyslipidemia & $135(52.5)$ & $341(55)$ & 0.504 \\
\hline Obesity & $63(24.5)$ & $176(28.4)$ & 0.241 \\
\hline Underweight & $11(4.3)$ & $22(3.5)$ & 0.604 \\
\hline Ischaemic heart disease & $25(9.7)$ & $126(20.3)$ & $<0.001$ \\
\hline Heart failure & $17(6.6)$ & $77(12.4)$ & 0.011 \\
\hline Atrial fibrillation & $30(11.7)$ & $122(19.7)$ & 0.004 \\
\hline Heart disease & $57(22.2)$ & $224(36.1)$ & $<0.001$ \\
\hline Cerebrovascular accident & $13(5.1)$ & $58(9.4)$ & 0.034 \\
\hline Mood disorder & $14(5.4)$ & $43(6.9)$ & 0.416 \\
\hline Osteoporosis & $4(1.6)$ & $13(2.1)$ & 0.597 \\
\hline Bronchial asthma & $29(11.3)$ & $82(13.2)$ & 0.431 \\
\hline Neoplasia & $34(13.2)$ & $92(14.8)$ & 0.536 \\
\hline $\mathrm{CCl} \geq 3$ & $56(21.8)$ & $236(38.1)$ & $<0.001$ \\
\hline $\mathrm{CCl}$, median (IQR) & $1(1)$ & $2(2)$ & $<0.001$ \\
\hline
\end{tabular}

Bold indicates $\mathrm{p}$ value $<0.05$

$B M I$ body mass index; $F E V$ forced expiratory volume in $1 \mathrm{~s} ; F V C$ forced vital capacity; $C C I$ Charlson comorbidity index score, not age-adjusted; $m M R C$ modified Medical Research Council scale; SpO2 peripheral oxygen saturation by means of pulse oximetry measured with the patient at rest in a sitting position; BiPAP bi-level positive airway pressure; CPAP continuous positive airway pressure; IQR interquartile range

should be drawn with caution as there may be a survival bias. Our study population may represent individuals who had recovered from their severe exacerbation for suffering a less severe form of the disease than admitted patients who did not overcome the exacerbation [40].
Hence, larger studies are needed to specifically analyse this group of patients and confirm our results.

This is the first multicentre study in the Canary archipelago that characterises patients with COPD who attend pneumology outpatient services. Its main strength lies in the large sample size and in the good 
characterization of the population. Although the study was carried out within a specialist-care setting, the high percentage of patients designated low risk according to GesEPOC 2021 may offer an initial view on individuals with relatively mild disease, a point to be confirmed in future studies.

In conclusion, the patient population with COPD in the Canary archipelago is characterised by a high rate of active smokers, T2DM, and cardiovascular disease, which presumably adds complexity to disease management. The high prevalence of heart disease in our patients with COPD, particularly in those exhibiting more symptoms, corroborates the need to actively seek these patients.

\section{Limitations}

The main limitation of this study is a potential information bias due to the recorded variables from the patients' medical records. In addition, we must take into account the limitations of a cross sectional observational study. The temporal sequence of the variables studied could not be established, making it difficult to separate risk factors from prognostic factors. Furthermore, although five of the eight islands of the Canary archipelago are not represented in this study, the selected islands cover more than $80 \%$ of the Canary Island population, which adds to the validity of our results offering an overall vision of the patient with COPD in this region.

\footnotetext{
Abbreviations

AHT: Arterial hypertension; AF: Atrial fibrillation; BMI: Body mass index; BiPAP: Bi-level positive airway pressure; CCl: Charlson comorbidity index score, not age-adjusted; CHF: Chronic heart failure; COPD: Chronic Obstructive Pulmonary disease; CPAP: Continuous positive airway pressure ventilation; CVA: Cerebrovascular accidents; DLP: Dyslipidaemia; FEV1: Forced expiratory volume in 1s; FVC: Forced vital capacity; GesPOC: Spanish Guideline of Chronic Obstructive Pulmonary Disease; GOLD: Global Initiative for Chronic Obstructive Lung Disease; IHD: Ischaemic heart disease; mMRC: Modified Medical Research Council scale; PYI: Pack-year index; SD: Standard deviation; SpO2: Peripheral oxygen saturation by means of pulse oximetry; T2DM: Type 2 diabetes mellitus.
}

\section{Supplementary Information}

The online version contains supplementary material available at https://doi. org/10.1186/s13104-022-05930-7.

\section{Additional file 1: Table S1. Baseline characteristics of patients with chronic obstructive pulmonary disease according smoking status.}

Additional file 2: Fig. S1. Morbidity in patients with COPD according to the Spanish guidelines GesEPOC 2021 risk groups.

\section{Acknowledgements}

Not applicable.

\section{Authors' contributions}

JMFG conceived the study, designed and drafted the manuscript, and participated in data collection, analysis, and interpretation. JMHP participated in study and manuscript design, data collection, analysis, and interpretation. ALWP participated in study and manuscript design, data collection, analysis, and interpretation. CCL: participated in study and manuscript design, data collection, analysis, and interpretation. IGT: participated in study and manuscript design, data collection, analysis, and interpretation. YRF analysed and interpreted the data and assisted in drafting the manuscript. CRI, LMGG and SGD participated in data collection and helped to draft the manuscript. All authors read and approved the final manuscript.

\section{Funding}

Publishing this article as an open access version was only made possible with the unconditional support of Boehringer Ingelheim. However, they have not made any financial contribution to the health care personnel neither they contributed to the study design, data collection, statistical analysis or the writing of the manuscript.

\section{Availability of data and materials}

The datasets used, analysed or both during the current study are available from the corresponding author on reasonable request. The datasets generated and analysed during the current study are not available to researchers outside of the co-investigators due to data protection laws.

\section{Declarations}

\section{Ethics approval and consent to participate}

The study was approved by the Ethics Committee for Clinical Research of the University Hospital Nuestra Señora de Candelaria, registry number CHUNSC_2021_41; retrospective, clinical data extraction from medical records was authorised by the corresponding ethics committees, who waived the need for informed consent.

\section{Consent for publication}

Not applicable. Data was collected retrospectively from the patients' electronic, medical record, so that the regional ethics committee waived the need for informed consent.

\section{Competing interests}

The authors declare not to have any conflict of interest related to this article.

\section{Author details}

${ }^{1}$ Pneumology and Thoracic Surgery Service, Unit for Patients with Highly Complex COPD, University Hospital Nuestra Señora de Candelaria, Santa Cruz de Tenerife, Spain. ${ }^{2}$ University Institute of Tropical Disease and Public Health of the Canary Islands, University of La Laguna, Santa Cruz de Tenerife, Spain. ${ }^{3}$ Pneumology Service, University Hospital Dr. Negrín, Gran Canaria, Spain. ${ }^{4}$ Pneumology Service, San Juan de Dios Hospital, Tenerife, Spain. ${ }^{5}$ Foundation of the Canary Islands Health Research Institute (FIISC), Santa Cruz de Tenerife, SpainHealth Services Research on Chronic Patients Network (REDISSEC), Madrid, Spain. ${ }^{6}$ Primary Care Centre of the Canary Islands Public Health Service, Breña Baja, La Palma, Santa Cruz de Tenerife, Spain.

Received: 12 December 2021 Accepted: 26 January 2022

Published online: 10 February 2022

\section{References}

1. Fromer L. Implementing chronic care for COPD: planned visits, care coordination, and patient empowerment for improved outcomes. Int J Chron Obstruct Pulmon Dis. 2011;6:605-14.

2. Chapman KR, Mannino DM, Soriano JB, Vermeire PA, Buist AS, Thun MJ, et al. Epidemiology and costs of chronic obstructive pulmonary disease. Eur Respir J. 2006;27:188-207.

3. Perera PN, Armstrong EP, Sherrill DL, Skrepnek GH. Acute exacerbations of COPD in the United States: inpatient burden and predictors of costs and mortality. COPD. 2012;9:131-41. 
4. Global Initiative for Chronic Obstructive Lung Disease - GOLD 2021 https://goldcopd.org/2021-gold-reports/. Accessed 22 Oct 2021.

5. Sode BF, Dahl M, Nordestgaard BG. Myocardial infarction and other co-morbidities in patients with chronic obstructive pulmonary disease: a Danish nationwide study of 74 million individuals. Eur Heart J. 2011;32:2365-75.

6. Almagro P, Cabrera FJ, Diez-Manglano J, Boixeda R, Recio J, Mercade J, et al. Comorbidome and short-term prognosis in hospitalised COPD patients: the ESMI study. Eur Respir J. 2015;46:850-3.

7. Alter P, Mayerhofer BA, Kahnert K, Watz H, Waschki B, Andreas S, et al. Prevalence of cardiac comorbidities, and their underdetection and contribution to exertional symptoms in COPD: results from the COSYCONET cohort. Int J Chron Obstruct Pulmon Dis. 2019;14:2163-72.

8. Figueira Gonçalves JM, García Bello MÁ, Martín Martínez MD, Pérez Méndez LI, García-Talavera I, García Hernández S, et al. The COPD comorbidome in the light of the degree of dyspnea and risk of exacerbation. COPD. 2019;16:104-7.

9. Figueira Gonçalves JM, Martín-Martinez MD, Pérez Méndez LI, GarcíaBello MA, García-Talavera I, García Hernández S, et al. Health status in patients with COPD according to GOLD 2017 classification: use of the COMCOLD score in routine clinical practice. COPD. 2018;15(4):326-33.

10. Figueira Gonçalves JM, García Bello MÁ, Martín Martínez MD, GarcíaTalavera I, Golpe R. Can the COPD-comorbidome be applied to all outpatients with chronic obstructive pulmonary disease? A single-center analysis. Arch Bronconeumol (Engl Ed). 2019;55:591-3.

11. Figueira Gonçalves JM. Cardiovascular Disease in a Canary Island Patient with chronic obstructive pulmonary disease: "Spicy Sauce for Our Wrinkled Potatoes." Arch Bronconeumol (Engl Ed). 2020;56:57-8.

12. Charlson ME, Pompei P, Ales KL, MacKenzie CR. A new method of classifying prognostic comorbidity in longitudinal studies: development and validation. J Chronic Dis. 1987;40:373-83.

13. Miravitlles M, Calle M, Molina J, Almagro P, Gómez JT, Trigueros JA, et al. Spanish COPD guidelines (GesEPOC) 2021: updated pharmacological treatment of stable COPD. Arch Bronconeumol (Engl Ed). 2021:S0300-2896(21):00103-4.

14. Soriano JB, Alfageme I, Miravitlles M, de Lucas P, Soler-Cataluña JJ, GarcíaRío F, et al. Prevalence and determinants of COPD in Spain: EPISCAN II. Arch Bronconeumol (Engl Ed). 2021;57:61-9.

15. Calle Rubio M, Soler-Cataluña JJ, López-Campos JL, Alcázar Navarrete B, Rodríguez González-Moro JM, Soriano JB, et al. Assessing the clinical practice in specialized outpatient clinics for chronic obstructive pulmonary disease: Analysis of the EPOCONSUL clinical audit. PLOS ONE. 2019;14:e0211732.

16. Jiménez CA, Masa F, Miravitlles M, Gabriel R, Viejo JL, Villasante C, et al. Smoking characteristics: attitudes and dependence. Differences between healthy smokers and smokers with COPD. Chest. 2001;119:1365-70.

17. Alcázar-Navarrete B, Trigueros JA, Riesco JA, Campuzano A, Pérez J. Geographic variations of the prevalence and distribution of COPD phenotypes in Spain: "The ESPIRAL-ES study" Int J Chron Obstruct Pulmon Dis. 2018;13:1115-24.

18. van Eerd EA, van der Meer RM, van Schayck OC, Kotz D. Smoking cessation for people with chronic obstructive pulmonary disease. Cochrane Database Syst Rev. 2016;2016:CD010744.

19. Anthonisen NR, Connett JE, Kiley JP, Altose MD, Bailey WC, Buist AS, et al. Effects of smoking intervention and the use of an inhaled anticholinergic bronchodilator on the rate of decline of FEV1. The Lung Health Study. JAMA. 1994;272:1497-505.

20. Pelkonen M, Notkola IL, Tukiainen H, Tervahauta M, Tuomilehto J, Nissinen A. Smoking cessation, decline in pulmonary function and total mortality: a 30 year follow up study among the finish cohorts of the seven countries study. Thorax. 2001;56:703-7.

21. Shahab L, Jarvis MJ, Britton J, West R. Prevalence, diagnosis and relation to tobacco dependence of chronic obstructive pulmonary disease in a nationally representative population sample. Thorax. 2006;61:1043-7.

22. Clark KD, Wardrobe-Wong N, Elliott JJ, Gill PT, Tait NP, Snashall PD. Cigarette smoke inhalation and lung damage in smoking volunteers. Eur Respir J. 1998;12:395-9.

23. Jimenez-Ruiz CA, Masa F, Miravitlles M, Gabriel R, Viejo JL, Villasante C, et al. Smoking characteristics: differences in attitudes and dependence between healthy smokers and smokers with COPD. Chest. 2001;119:1365-70.
24. National Cancer Institute. World Health Organization; The Economics of Tobacco and Tobacco Control. National Cancer Institute Tobacco Control Monograph. 21. NIH Publication No. 16-CA-8029A. Bethesda, MD: U.S. Department of Health and Human Services, National Institutes of Health, National Cancer Institute; and Geneva, CH: World Health Organization; 2016. Accessed 6 Aug 2021.

25. Hernández Pérez JM, Jadraque Jiménez P, Sánchez Castro AL, Gómez Aragón FJ. Prevalence of tobacco consumption among healthcare workers on the island of La Palma. Med Gen y Fam. 2015;4:63-7.

26. Carrasco Garrido de Miguel Díez JR, Gutiérrez J, Centeno AM, et al. Negative impact of chronic obstructive pulmonary disease on the healthrelated quality of life of patients. Results of the EPIDEPOC study. Health Qual Life Outcomes 2006;23:31.

27. Castaño-Abad MT, Montserrat-Capdevila J, Godoy P, Marsal JR, Ortega M, Alseda $M$, et al. Diabetes as a risk factor for severe exacerbation and death in patients with COPD: a prospective cohort study. Eur J Public Health. 2020;30:822-7.

28. de Lucas-Ramos P, Izquierdo-Alonso JL, Rodriguez-Gonzalez Moro JM, Frances JF, Lozano PV, Bellón-Cano JM, CONSISTE study group. Chronic obstructive pulmonary disease as a cardiovascular risk factor Results of a case-control study (CONSISTE study). Int J Chron Obstruct Pulmon Dis. 2012;7:679-86.

29. Divo M, Cote C, de Torres JP, Casanova C, Marin JM, Pinto-Plata V, et al. Comorbidities and risk of mortality in patients with chronic obstructive pulmonary disease. Am J Respir Crit Care Med. 2012;186:155-61.

30. Miller J, Edwards LD, Agustí A, Bakke P, Calverley PM, Celli B, et al. Evaluation of COPD longitudinally to identify predictive surrogate Endpoints (ECLIPSE) Investigators. Comorbidity, systemic inflammation and outcomes in the ECLIPSE cohort. Respir Med. 2013;107:1376-84.

31. Mannino DM, Thorn D, Swensen A, Holguin F. Prevalence and outcomes of diabetes, hypertension and cardiovascular disease in COPD. Eur Respir J. 2008;32:962-9.

32. Westerik JA, Metting El, van Boven JF, Tiersma W, Kocks JW, Schermer TR. Associations between chronic comorbidity and exacerbation risk in primary care patients with COPD. Respir Res. 2017;18:31.

33. Lahousse L, Tiemeier H, Ikram MA, Brusselle GG. Chronic obstructive pulmonary disease and cerebrovascular disease: a comprehensive review. Respir Med. 2015;109:1371-80.

34. Figueira Gonçalves JM, García Bello MÁ, Golpe R, Alonso Jerez JL, GarcíaTalavera I. Impact of diabetes mellitus on the risk of severe exacerbation in patients with chronic obstructive pulmonary disease. Clin Respir J. 2020;14:1208-11.

35. Fedeli U, De Giorgi A, Gennaro N, Ferroni E, Gallerani M, Mikhailidis DP, et al. Lung and kidney: a dangerous liaison? A population-based cohort study in COPD patients in Italy. Int J Chron Obstruct Pulmon Dis. 2017;12:443-50.

36. Callerubio M, Casamor MM, On behalf of the FENEPOC study group. Identification and distribution of COPD phenotypes in clinical practice according to Spanish COPD Guidelines: the FENEPOC study. Int J COPD. 2017;12:2373-83

37. Pozo-Rodríguez F, López-Campos JL, Alvarez-Martínez CJ, Castro-Acosta A, Agüero R, Hueto J, et al; AUDIPOC Study Group. Clinical audit of COPD patients requiring hospital admissions in Spain: AUDIPOC study. PLoS One. 2012;7:e42156.

38. Lin L, Shi J, Kang J, Wang Q. Analysis of prevalence and prognosis of type 2 diabetes mellitus in patients with acute exacerbation of COPD. BMC Pulm Med. 2021;21:7.

39. Xiaolong L, Zhen W, Mingyue X, Wei D. Smoking status affects clinical characteristics and disease course of acute exacerbation of chronic obstructive pulmonary disease: a prospectively observational study. Chron Respir Dis. 2020;17:1479973120916184.

40. Soler-Cataluña JJ, Martínez-García MA, Román Sánchez P, Salcedo E, Navarro M, Ochando R. Severe acute exacerbations and mortality in patients with chronic obstructive pulmonary disease. Thorax. 2005;60:925-31.

\section{Publisher's Note}

Springer Nature remains neutral with regard to jurisdictional claims in published maps and institutional affiliations. 